\title{
PROPERTIES OF NARROW-GAP SOLID SOLUTIONS OF NEAR INFRARED BAND OPTOELECTRONIC DEVICES
}

\author{
A.V. Blagin \\ Department of Physics \\ Don State Technical University \\ Rostov-on-Don, Russia \\ a-blagin@mail.ru
}

\author{
N. A. Nefedova \\ Department of Physics and Electronics \\ Platov South-Russian State Polytechnic University (NPI) \\ Novocherkassk, Russia \\ ubahoba77@mail.ru
}

\author{
V.V. Nefedov \\ Department of General Engineering Disciplines \\ Platov South-Russian State Polytechnic University (NPI) \\ Novocherkassk, Russia \\ nvvnpi@gmail.com
}

\begin{abstract}
The paper consists of analysis of the results obtained in the course of experiments on creation of lightemitting solid solutions on the basis of Gallium antimonide within the framework of the gradient liquid phase epitaxy method. Analysis of the kinetics of the crystallization process in epitaxial layers shows that the speed of $\mathrm{GaBi}$ melt migration increases along with concentration of Bismuth in the melt and rise of temperature of thermomigration, which permits to manage the operational properties of solid solution composition of the created material. Experiments on research of the structural perfection of layers GsSbBi show that the dislocation density on the surface of the "matrix-layer" section is higher than in the solid solution and substrate. It is found that the method of gradient liquid phase epitaxy is preferred for obtaining of hardware components for optoelectronics with IR diapason. The paper also suggests a constructive outline for use of materials as hardware components of light-emitting diode.
\end{abstract}

Keywords - solid solution, gradient epitaxy, small mesa diode, Gallium antimonide, solid junction, photo-luminescence spectra.

\section{INTRODUCTION}

Increasing interest is shown in the solid solutions (SS) used in the infrared technologies such as A3B5 with solid junction less than $1 \mathrm{eV}$ being perspective as optoelectronic converters. Introduction of isovalent elements into the operating layers followed by the modification of the energetic structure of semiconductor (for layers on the basis of $\mathrm{GaSb}-$ Phosphor, Bismuth) allows management of optical parameters of the active area of electronic materials.

A case of interest is the use of Bismuth not only as a component in position of the B5 element in the crystal lattice, but also securing the increase in stability of growth at the stage of phase transition [1,2]. The mentioned works also contain information about transferring of the solid solution to stoichiometric compound, its variation in coordinate towards crystallization, guided change in optical parameters of the materials crystallized from enriched Bi melts. The impediment here is low solubility of Bismuth and its passive transposition during the diffusion-controlled crystallization in the temperature gradient field.

The paper explores the growth processes in solid solutions within the gradient temperature field. This method is known as "gradient solid phase epitaxy" (GSPE), "melt thermal migration" (MTM); it shows the development of the method of "zonal melt with temperature gradient" from the 1950-70s [3]. Let us enlist the main features and scope of the GSPE method used for obtaining of $\mathrm{AB}_{1-\mathrm{x}} \mathrm{C}_{\mathrm{x}}$ layers on linear zones: 1 ) in the GSPE method, the values of excess densities of components necessary for growth supply are very low, therefore the growth proceeds in conditions that are at the maximum rate close to the balanced and exclude the risks of development of bulk crystal growth; 2) crystallization is performed out of the thin layer of melt enclosed between the substrates which has a set of universally recognized advantages; 3 ) high isothermality of the process simplifies the technology and lifts restrictions combined with the effects of cooling rate. Due to the mentioned features the GSPE method shows a set of advantages: driving force of the process provides for achievement of significantly high growth rates and, along with that, it is well managed; the possibility to perform an uninterrupted replenishment from the source crystal is secured with no corruption of the process equilibrium; hardware and the technology itself are relatively noncomplicated which provides for a possibility to produce thin epitaxial foils and voluminous layers with structures that are successfully controlled in terms of area and thickness. The displacement of the linear zone through the semiconductor matrix gives a three-layer structure, which, with appropriate selection of the zone master alloy and the original semiconductor, contains two parallel $p$-n junctions. Width of layers in structure is defined by size of virgin crystal, zones and clearance between them; characteristics of the produced 
solid solution are defined by melt composition and temperature-time regime of GSPE [4,5].

Important feature of the GSPE on the linear zones is a possibility to obtain multi-layer structure in one technological cycle having any amount of identical or different layers which provides for identity in properties of generated p-n-junctions. This peculiarity is used to obtain Gunn diodes (bulk negative conductivity diodes), integrated multi-channel photo-receivers and photo-emission systems and other semiconductor items.

\section{PRINCIPLES OF THE METHOD AND STATEMENT}

Temperature range from 890 up to $910 \mathrm{~K}$ is defined for crystallization processes in solid solutions with due regard of the before-mentioned factors. The upper limit depends on the rapid growth of the thermomigration speed and, therefore, on increase in defect density. The lower limit corresponds to the beginning of the crystallization process during which the wetting of matrix by the melt is full for the first time.

Regimes of the GSPE process in the framework of selected diapason were adapted according to such parameters as wave length corresponding to the solid junction (calculation according to the band gap energy of the binary components of the solid solution), small lattice mismatch (less than $0,4 \%$ ), small mismatch in thermal expansion coefficients (TEC) in a growing solid solution and matrix (less than 10\%). Homogenization is performed at the temperatures that were $150 \mathrm{~K}$ higher than the growth temperature with no Gallium antimonide substrate $(\mathrm{TL}=985 \mathrm{~K})$ during $150 \mathrm{~min}$. The next step consists of cooling up to $\mathrm{T}=295$ with further shaping of sandwich-type growth composition limited by two Gallium antimonide substrates (100).

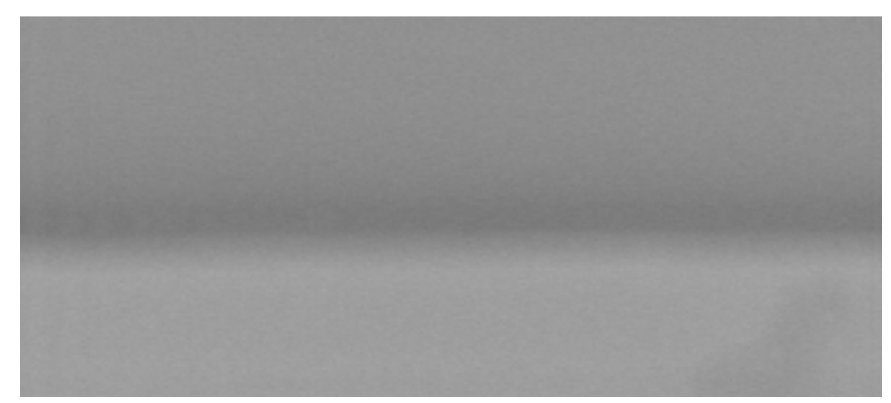

Fig. 1. Lateral chip of solid solution GaSbBi $(\times 800)$

After the melt is additionally homogenized at the temperature that is higher than the growth temperature by $5 \div 7$ $\mathrm{K}$ during 45 minutes, the temperature is decreased according to the predicted value $\Delta \mathrm{T}$ from 7 to $17 \mathrm{~K}$ depending of the estimated composition.

Furnace design allows backing of the operation level of the temperature gradient up to $40 \mathrm{~K} / \mathrm{cm}$. Thickness of the melt fluctuated from 25 to $200 \mu \mathrm{m}$. The layers of GaSbBi solid solution had high structural perfection with distinct substratelayer interface (see Fig. 1).

Kinetics of layer growth is studied to define technological parameters of shaping of solid solutions with instrumental quality. Experimental dependence of growth speed on the zone thickness is defined according to the time stamp method described in [4].

\section{RESULTS AND DISCUSSION OF THE AUTHORS' RESEARCH}

Figure 2 features experimental dependencies growth rate as function of melt thickness The area of growth rate is registered everywhere (at thicknesses of less than $40 \mu \mathrm{m}$ ) along with decrease in influence of thickness with diffusion control (at melt thicknesses of $100 \mu \mathrm{m}$ and more). Migration rate of a mixed melt $(\mathrm{GaBi})$ grows in cases when share of Bismuth is increased.

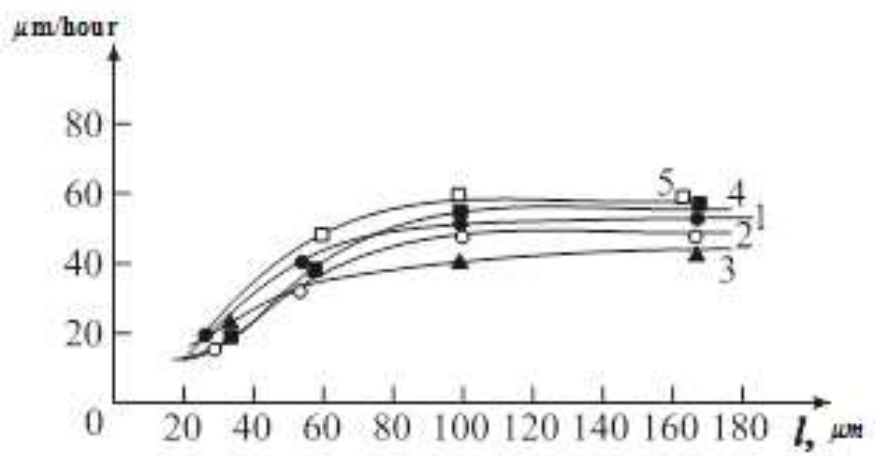

Fig. 2. Growth rate as function of melt thickness for GaSb systems (curve 4, melt - Gallium, temperature $900 \mathrm{~K}$ ) and GaSbBi (composition of zones GaBi 0.7-0.3 - curve 1, 0.6-0.4 - curve 5, temperature $897 \mathrm{~K}$, composition of zones $\mathrm{GaBi}$ 0.6-0.4 - curve 2, temperature $906 \mathrm{~K}, \mathrm{GaBi}$ $0.2-0.8$, curve 3 , temperature $906 \mathrm{~K}$ )

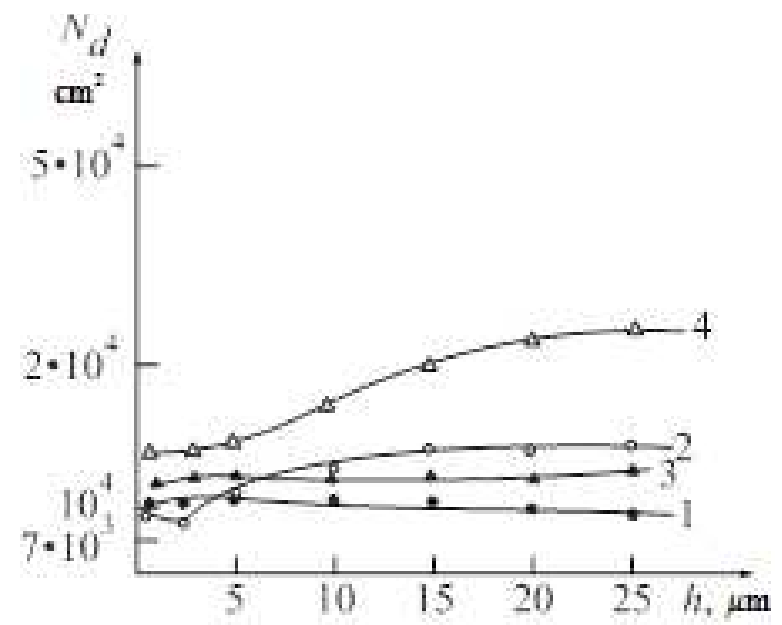

Fig. 3. Distribution of density of dislocations along the thickness of layers $\mathrm{GaSb}(2), \mathrm{GaSb}_{0.997} \mathrm{Bi}_{0.003}(4), \mathrm{T}=897 \mathrm{~K}, \mathrm{GaSb}_{0.995} \mathrm{Bi}_{0.005}(3), \mathrm{T}=897 \mathrm{~K}$, and $\mathrm{GaSb}_{0.995} \mathrm{Bi}_{0.005}(1), \mathrm{T}=906 \mathrm{~K}$

Research of composition grown from solid solution of Gallium antimonide-bismuthide represents the solubility of $\mathrm{Bi}$ on the level of not more than 0,5 atomic percent corresponding to the data from $[1,2,6]$. Analysis of structural perfection of layers in $\mathrm{GaSbBi} / \mathrm{GaSb}$ solid solution is based on the research of dislocation profile of the layer - through chip, by means of layer-by-layer etching. Density of dislocations arrives at high values $\left(\mathrm{N}_{\mathrm{D}}>2 * 10^{4} \mathrm{~cm}^{-2}\right)$ on the surface of matrix-layer interface, which is higher than in the layer. Leap of composition on heterointerface is indicative of a high value of 
elastic strains in the layer and, consequently, their impact on energy structure of charge carriers in layer.

Figure 3 represents the molecular sieve effect noticed in the paper [4] (curves 1,2,4) - decrease in density of defects along the layer growth coordinate. It is apparent that the decrease in density of dislocations is promoted by the increase of Bi solubility and increase of growth rate up to $906 \mathrm{~K}$.

Dependence of concentration of electrons on the growth coordinate is studied by means of two methods [8]: a) fluorescent method - according to the known dependence of spectral bandwidth of solid junction on concentration of carriers and according to intensity of the emission band curve; b) Hall method - conductivity type, concentration of electrons and their mobility were measured on the basis of measurement of Hall coefficient in weak magnetic field and specific conductivity of the material. Dependence of concentration of electrons on the growth coordinate for systems $\mathrm{GaSb}_{0.997} \mathrm{Bi}_{0.003}$ и $\mathrm{GaSb}_{0.995} \mathrm{Bi}_{0.005}$ is represented in Fig. 4.

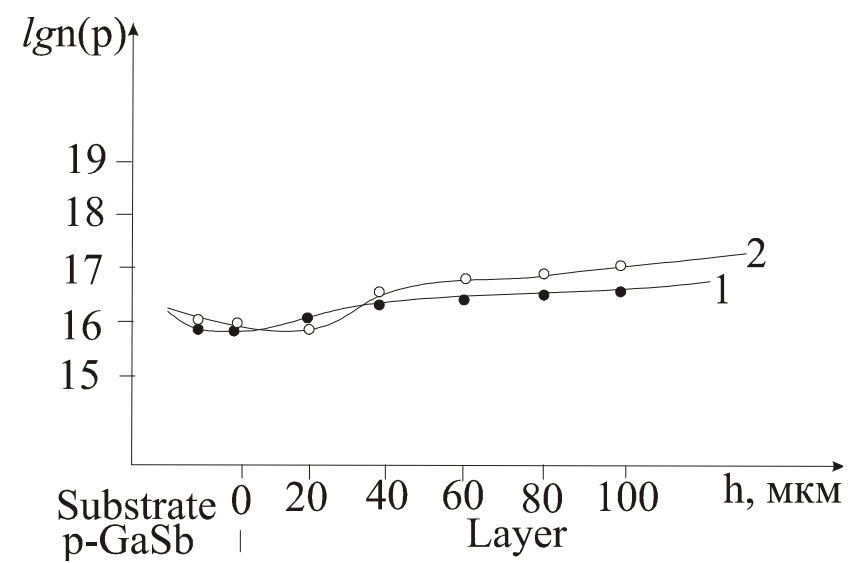

Fig. 4. Distribution of carriers in GaSbBi solid solution along the growth coordinate: $1-\mathrm{GaSb}_{0.997} \mathrm{Bi}_{0.003} \div \mathrm{Zn}, 2-\mathrm{GaSb}_{0.995} \mathrm{Bi}_{0.005} \div \mathrm{Zn}$

Figure 4 features three characteristic zones. On curve 1 (impurity $\mathrm{Zn}, \mathrm{GaSb}_{0.997} \mathrm{Bi}_{0.003}$ ), the concentration of electrons in the area of layer being the nearest to the substrate initially falls, than rises at big thicknesses ( $h>30$ мкм) and arrives at its maximum values at the thickness of $55 \mu \mathrm{m}$; curve 2 corresponds to the layer with high share of Bi (impurity $\mathrm{Zn}$, $\left.\mathrm{GaSb}_{0.995} \mathrm{Bi}_{0.004}\right)$, concentration of electrons at heterointerface is significantly dropped, but later this drop is followed by a certain increase.

Results of the research of distribution and mobility of electrons in epitaxial layers are listed in table 1. The accumulated data allows to suggest the fact of increase in charge carriers concentration (compared to its values in the Gallium antimonide matrix with increase in Bi concentration).
Table I. Mobilities and concentration of charge carriers electrons in layers of $\mathrm{GaSb}_{1-\mathrm{x}} \mathrm{Bi}_{\mathrm{x}}$ solid solutions at $295 \mathrm{~K}$

\begin{tabular}{|c|c|c|}
\hline $\begin{array}{l}\mathrm{x}, \quad \text { mole } \\
\text { fraction }\end{array}$ & $\mu, \mathrm{cm}^{2} \times \mathrm{B}^{-1} \times \mathrm{c}^{-1}$ & $\begin{array}{l}\text { Electron density, } \\
\times 10^{-16} \mathrm{~cm}^{-3}\end{array}$ \\
\hline 0 & 2800 & 1,2 \\
\hline 0,0020 & 7200 & 2,4 \\
\hline 0,0025 & 7500 & 2,8 \\
\hline 0,0030 & 7100 & 4,7 \\
\hline 0,0050 & 8200 & 7,3 \\
\hline
\end{tabular}

The major significance in terms of application of the test materials is attributed to the optical properties of solid solutions. The study of photoluminescent characteristics of Gallium antimonide-bismuthide compared to the substrate material $(\mathrm{GaSb})$ can provide evidence of the following differences: shift in maximum of luminescence spectral band depending on the composition of epitaxial layer; change in characteristics combined with particular qualities of the energy structure of the material compared to the substrate $\mathrm{GaSb}$ and generation of nonradiative-recombination centers. The physics of changes in optical properties consists of the process of transition of charge carriers from the direct minimum to the indirect minimum combined with a correspondent increase in contribution of nonradiative-recombination acts.

Photoluminescent specters of GaSbBi/GaSb solid solutions are represented on Fig. 5. Energy structure of $\mathrm{GaSb}$ is insignificantly changed after introduction of Bismuth due to its low density in solid solution, although the change in value of the fundamental transition is already about $1 \mathrm{meV}$, which provides for a possible application of the researched solid solution in light emitting diode structures with varied wave length.

Direct band gap Gallium antimonide GaSb has band gap width described by the dependence [1] (interval close to 1,7 $\mu \mathrm{m})$.

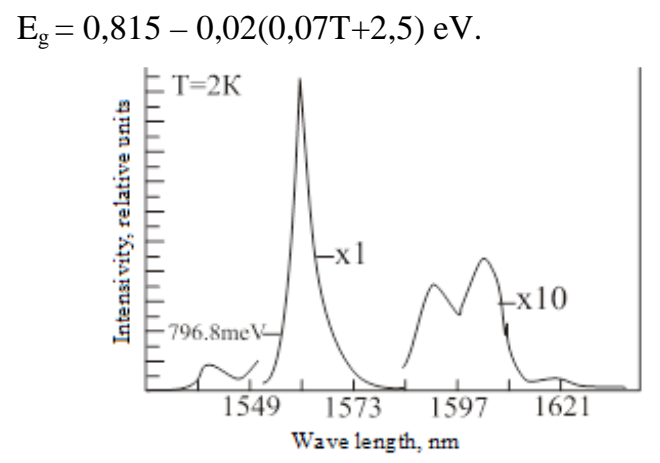

Fig. 5. Photoluminescent characteristics of $\mathrm{GaSb}_{0.998} \mathrm{Bi}_{0.002}$ solid solution 


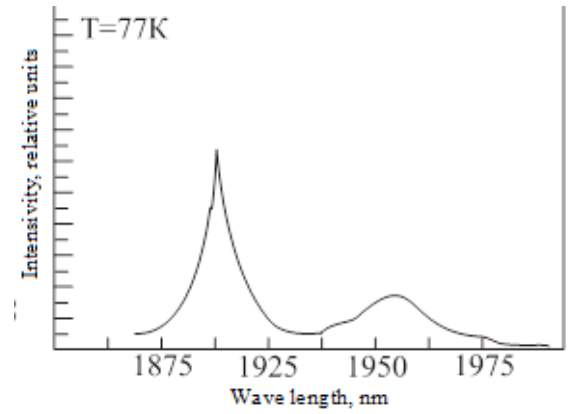

Fig. 6. Photoluminescent characteristics of $\mathrm{GaSb}_{0.995} \mathrm{Bi}_{0.005}$ solid solution

Photoluminescent characteristics and intensity of recombination luminescence along the growth coordinate are defined on the angle laps of structures [8]. Plane inclination angle of a new lap varies from 0,1 to $10^{\circ}$. Error rate of the calculation of position of maximum of specters is $0,001 \mathrm{eV}$. Depending on the composition of solid solution half-width of radiation curve changes in the limits of $25-60 \mathrm{meV}$ at the $\mathrm{T}=77 \mathrm{~K}$ showing shows a high structural perfection of samples.

The traditional method of reducing the threshold radiation current is the use of strip geometry. This method is based on the limitation of the pumping region of the laser crystal, which is associated with high values of the current density in the working region of the crystal.

Narrowing of the electron motion area is achieved, as a rule, by two means: use of plane layers with narrow terminal strip and use of structures with built-in current constraint. Fig. 7 shows schematic picture of small mesa strip-geometry laser diode [9]. Laser generation is for the first time performed at the room temperature on the laser light-emitting diodes $[10,11,12]$, therefore the technology of optoelectronic devices can be enhanced by such construction for sources of coherent radiation being active in the spectral interval close to $1,85 \mu \mathrm{m}$.

Changes in electromagnetic parameters are subject to the modification of electronic structure, in particular, presence of Bismuth in solid phase which is generally characteristic for complex systems, as it is shown in the present paper and in other literature $[1-4,6,8]$ containing the description of correspondent mechanisms of modification of physical properties of materials used in electronic devices.

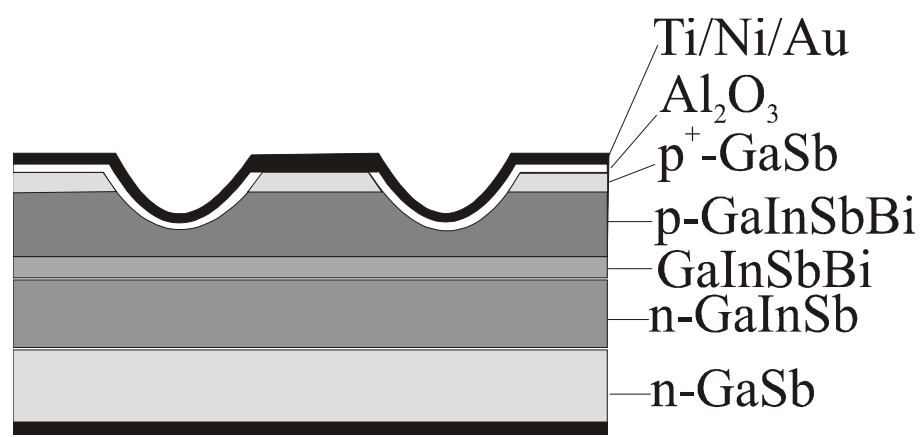

Fig. 7. Scheme of a laser light-emitting diode with strip geometry

\section{CONCLUSION}

The paper contains a description of properties of new materials used in optoelectronic devices - solid solutions GaSb1-xBix $(x \leq 0,005)$ obtained by means of gradient liquid phase epitaxy method.

The researched materials will be effectively applied in long-wave fiber-optic communication lines, infrared sensors in gas analyzers and other IR-devices as well as IR-spectrometric devices for analysis of various materials and media. Evaluations of radiation leakages in optic fiber in the diapason close to $1,9 \mu \mathrm{m}$, performed by the authors, don't exceed 0,01 $\mathrm{dB} / \mathrm{km}$. This is the next lower order to the existing values of the traditional IR diapasons close to 1,3 and $1,55 \mu \mathrm{m}$.

Analysis of the kinetics of the crystallization process of epitaxial layers showed that the migration rate of galliumbismuth melt increases with the concentration of bismuth in the melt and an increase in the temperature of thermomigration, which makes it possible to control the composition of the solid solution by the performance characteristics of the material being formed.

Experiments aimed to study the structural perfection of GaSbBi layers have shown that the dislocation density at the matrix-layer interface is higher than in the solid solution and substrate.

Consequently the $\mathrm{GaSbBi} / \mathrm{GaSb}$ solid solutions are advantageous materials in terms of coherent radiation active at the temperatures of up to $300 \mathrm{~K}$ in the diapason close to 1,85 $\mu \mathrm{m}$.

\section{References}

[1] V.N. Lozovskij, L. S. Lunin, A.V. Blagin, Gradientnaya zhidkofaznaya kristallizaciya mnogokomponentnyh poluprovodnikovyh materialov, Rostov-na-Donu: SKNC VSH, 2003, p. 376

[2] P. Gladkov, E. Monova, J. Weber, "Liquid phase epitaxy and photoluminescence characterization of p-type $\mathrm{GaSb}$ layers grown from Bi melts", J. Cryst. Growth, vol. 146, pp. 319-325, 1995.

[3] V.N. Lozovskij, Zonnaya plavka s gradientom temperatury, Moskva: Metallurgiya, 1972, p. 240

[4] V.N. Lozovskij, L.S. Lunin, V.P. Popov Zonnaya perekristallizaciya gradientom temperatury poluprovodnikovyh materialov, Moskva: Metallurgiya, 1987, p. 232

[5] A.V. Blagin, V.V. Kalinchuk, V.I. Lebedev, L.S. Lunin, Fizika kristallizacii i defektov tverdotel'nyh struktur na mikro- i nanourovne, Rostov-na-Donu: YUNC RAN, p. 288

[6] A.V. Blagin, V.V. Nefedov, N.A. Nefedova, "Prototyping of chemical composition of complex crystals using method of neural networks", IOP Conf. Ser.: Earth Environ, vol. 87, 2017.

[7] Y.P. Yakovlev, Infrakrasnaya optoehlektronika na osnove mnogokomponentnyh tverdyh rastvorov antimonida galliya, $\mathrm{SPb}$, 1995.

[8] V.F. Kovalenko, "Metody kontrolya ehpitaksial'nyh sloev v poluprovodnikah peremennogo sostava", Avtometriya, vol. 6, pp. 54 64, 1990.

[9] L.E. Vorob'ev, A.N. Sofronov, D.A. Firsov, "Lazernye diody dlya fotodinamiki”, Fotonika, vol. 1, pp. 20-23, 2012.

[10] Y. Suehmacu, S. Kataoka, K. Kisino, Osnovy optoehlektroniki, Moskva: Mir, 1988, p. 288.

[11] A.V. Blagin, A.A. Barannik, A.S. Sevostiyanov, "Issledovanie uslovij formirovaniya mnogoslojnyh geterostruktur $\mathrm{InSb}$ i $\mathrm{GaSb}$ metodom 
zhidkostnoj ehpitaksii", Aktual'nye problemy tverdotel'noj ehlektroniki i miroehlektroniki, vol. 1, pp. 244-246, September 2004

[IXth Mezhdunar. nauch.-tekhn. konf. "Aktual'nye problemy tverdotel'noj ehlektroniki i miroehlektroniki”, p. 345, 2004]
[12] L.S. Lunin, I.A. Sysoev, L.V. Blagina, A.V. Blagin and A.A. Barannik "Temperature-Gradient Growth Kinetics and Macrodefects of GaInAs $<\mathrm{Bi}>$ Heterostructures", Inorganic Materials, vol. 45, pp. 841$845,2009$. 